\title{
Aportación bibliográfica Efraín Huerta (1914-1982). I
}

La bibliografía de y sobre el poeta y periodista Efraín Huerta que ofrecemos en este volumen es una contribución en homenaje a su memoria, al cumplirse diez años de su partida. Forma parte del material reunido en el Centro de Estudios Literarios a lo largo de más de veinte años. Esta información corresponde al tomo IV, actualmente en proceso, de la nueva edición del Dicciorario de escritores mexicanos. Siglo $\mathrm{XX}$, cuyo tomo I (A-CH) salió ai público en 1989 y los tomos II (D-F) y III (G) saldrán este año.

La bibliografía consta de cuatro partes: A) Libros de EH, clasificados en: A.1. Ensayos y prólogos, A.2. Poesía y A.3. Poemas en antologías y en otros libros. B) Hemerografía, clasificada en: B.1. Ensayos y B.2. Poesía. C) Homenajes. D) Referencias, en orden alfabético de críticos.

Agosto de 1992

Aurora M. Ocampo

LaURa NaVARrete Maya Instituto de Investigaciones Filológicas, UNAM 


\section{SIGLAS}

Ábs: Ábside. Revista. México.

Anuario PM: Anuario de la Poesía Mexicana. INBA. México.

BOI: Bloque de Obreros Intelectuales. Brújula: La Brújula en el Bolsillo.

Revista. México.

Búho: El Búho. Supl. dominical de Excélsior.

CasA: Casa de las Américas. Revista.

La Habana (Cuba).

CdeBA: Cuadernos de Bellas Artes.

Revista. INBA. México.

CdelT: Casa del Tiempo. Revista. UAM. México.

Centavo: El Centavo. Revista. Morelia, Mich. (México).

CL: Cuadernos de Literatura. Revista. México.

CLE: Revista de la Comunidad Latinoamericana de Escritores. México.

"Close up.": "Close up de nuestro cine." [Columna de notas y reseñas breves del autor publicadas en la RevMC].

CM: Cuademos de Marcha. Revista. México.

$C U$ : Cuadernos Universitarios. Revista. Universidad Autónoma de Nicaragua. León (Nicaragua).

CuA: Cuadernos Americanos. Revista. México.

$C u D$ : La Cultura al Día. Página cultural de Excélsior.

CuH: Cuadernos Hispanoamericanos. Revista. Madrid.

CuM: La Cultura en México. Supl. de la revista Siempre! México.

$C V$ : Cuadernos del Viento. Revista. México.

DC: Diorama de la Cultura. Supl. dominical de Excélsior.

DdeMéx: Diario de México. Diario. México.

Día: El Día. Diario. México.
EDIMUSA: Editores Mexicanos Unidos.

Edo.Mex: Estado de México. México. Exc: Excélsior. Diario. México.

FCE: Fondo de Cultura Económica. México.

FEM: Federación Editorial Mexicana.

GaCuba: Gaceta de Cuba. La Habana (Cuba).

GaFCE: Gaceta del FCE. FCE. México.

GalerasFCE: Galeras del FCE. FCE. México.

GaP: Gaceta Politécnica. IPN. México.

GaUNAM: Gaceta UNAM. México.

GI: El Gallo Ilustrado. Supl. dominical de El Día.

Gob. del Edo.: Gobiemo del Estado.

Guía: La Guía. Supl. dominical de Novedades.

HC: El Heraldo Cultural. Supl. dominical de El Heraldo de México. México.

"Hombre.": "El hombre de la esquina." [Columna política publicada en El Popular].

Hoy: Hoy. Revista. México.

HP: El Hijo Pródigo. Revista. México.- Ed. Facs. México: FCE, 1983.

INBA: Instituto Nacional de Bellas Artes. México.

IPN: Instituto Politécnico Nacional. México.

JL: La Jornada Libros. Supl. de La Jornada.

Jor: La Jomada. Diario. México.

JS: La Jornada Semanal. Supl. y revista dominical de La Jornada.

LeP: Letras Potosinas. Revista. San Luis Potosí, S.L.P. (México).

LI: La Letra y la Imagen. Supl. dominical de El Universal.

Libros.: "Libros y antilibros." [Columna de notas breves y anécdotas publicada en el $G I$. 
LM: Letras de México. Revista. México.- Ed. facs. México: FCE, 1984.

LV: El Libro y la Vida. Gaceta de Información y Crítica de El Día.

MA: México en el Arte. Revista. INBA. México.

Mañana: Mañana. Revista. México. MC: México en la Cultura. Supl. dominical de Novedades.

MLl: La Mesa Llena. Revista. México.

Nac: El Nacional. Diario. México.

NacD: El Nacional Dominical. Supl. dominical de El Nacional.

NBM: Nueva Biblioteca Mexicana.

Nexos: Nexos. Revista. México.

Nivel: Nivel. Gaceta de Cultura. México.

Nos: Nosotros. Revista. México.

Nov: Novedades. Diario. México.

Onda: La Onda. Supl. dominical de Novedades.

Ovaciones: Ovaciones. Supl. cultural de Ovaciones. Diario. México.

PdeP: Punto de Partida. Revista. UNAM. México.

PH: La Palabra y el Hombre. Revista.

UV. Xalapa, Ver. (México).

Plural: Plural. Revista. México.

Poesía RI: Poesía. Registro lberoamericano. México.

Pop: El Popular. Diario. México.

Pro: Proceso. Semanario. México.

Punto: Punto. Semanario. México.

RC: Revista Cultural. Supl. de El Universal.

Rev.: Revista.

RevBA: Revista de Bellas Artes. INBA. México.

RevMC: Revista Mexicana de Cultura. Supl. dominical de El Nacional.

RevS: Revista de la Semana. Supl. dominical de El Universal.

Rueca: Rueca. Revista. México.-- Ed. facs. México: FCE, 1984.

RUMex: Revista de la Universidad de
México. UNAM. México.

Ruta: Ruta. Revista. México- Ed. facs. México: FCE, 1982.

Sáb: Sábado. Supl. cultural de Unomásuno.

SBA: La Semana de Bellas Artes. Supl. de la Dirección de Literatura del INBA. México.

SC: El Semanario Cultural. Supl. dominical de Novedades.

SEP: Secretaría de Educación Pública. México.

Siempre!: Siempre! Revista. México.

SMC: El Sol de México en la Cultura. Supl. dominical de El Sol de México. Diario. México.

TA: Tierra Adentro. Revista. México. Taller: Taller. Revista. México.- Ed. facs. México: FCE, 1982.

Textual: Textual. Revista. México. TL: Tiempo Libre. Revista. México.

TN: Tierra Nueva. Revista. UNAM. México.

TP: Taller Poético. Revista. México.- Ed. facs. México: FCE, 1981.

U: Los Universitarios. Revista. UNAM. México.

UC: El Universal y la Cultura. Página cultural de El Universal.

UNAM: Universidad Nacional Autónoma de México. México.

Uni: El Universal. Diario. México.

Uno: Unomásuno. Diario. México.

UV: Universidad Veracruzana. Xalapa, Ver. (México).

Vuelta: Vuelta. Revista. México.

\section{A) LIBROS DE EH}

\section{A.1. ENSAYOS Y PRÓLOGOS}

Pról. Florecillas sitvestres. Por Ma. Antonieta Muñiz. Mćxico: Talls. Gráf. de la Nación, 1948. 
Maiakovski, poeta del futuro. México: Cvltura, 1956.

La causa agraria. México: Eds. del BOI, 1959.

Pról. [Breve explicación]. Poesía. 1935-1968. México: Mortiz, 1968. 7.

Pról. [Explicaciones]. Poemas prohibidos y de amor. México: Siglo XXI, 1973. 7-14.

Teatro Juárez. et.al. [Por los 75 años de su fundación]. Guanajuato, Gto.: Gob. del Edo, 1978.

Textos profanos. Cuadernos de Humanidades 11. México: UNAM, 1979.

Presentación en verso. Muchachos desnudos bajo el arcoiris de fuego. Once poetas jovenes latinuamericanos. Ed. Roberto Bolaño. Pról. Miguel Donoso Pareja. México: Extemporáneos, 1979. 9-11.

Pról. [Donde la locura...] Transa poética. México: ERA, 1980. 9-12.

Pról. [El poemínimo]. Estampida de poemínimos. Libros del Bicho 18. México: Premiá, 1980. 9-11.

Prólogos. [Prosa y verso]. Cuaderno de Humanidades 19. UNAM, 1981.

"Palabras por Abigael Bohorquez" [Poema]. Por Abigael Bohórquez. Heredad (1956-1978). Bibl. Selecta Alfem. México: FEM, 1981.

"Los españoles que viví." El exilio español en México (1939-1982). Explicación Salvador Reyes Nevares. Pról. José López Portillo. México: FCE/Salvat, 1982. 681-687.

Me vale madre. Dibujos Rogelio $\mathrm{Na-}$ ranjo. Próls. EH y Ríus. México: Eds. de Cultura Popular, s/a.

Pról. No olvides en tu sueño pensar que eres feliz. Por. Juan Manuel de Mora. Cuademos de Colibrí 1. México: s.e. s/a. 3-4.

Pról. Memorias de hospital. Presagio. Por Margarita Paz Paredes México: Miguel Ángel Porrúa, 1983.
Aquellas conferencias, aquellas charlas. Pról. Mónica Mansour. Textos de Humanidades 35. México: UNAM, 1983.

"El zarco Sabines." Uno es el poeta. Jaime Sabines y sus crílicos. Ed. Mónica Mansour. México: SEP, 1988. 27-29.

\section{A.2. POESIA}

Absoluto amor. México: Fábula, 1935. Línea del alba. México: Taller Poético, 1936.

Poemas de guerra y esperanza. Vidas, Hechos, Ideas. México: Eds. Tenochtitlán, 1943.

Los hombres del alba. Pról. Rafael Solana. México: Géminis, 1944.

La rosa primitiva. México: Nueva Voz, 1950.

Poesía. México: Canek, 1951.

Los poemas de viaje (1949-1953). Ilustr. A. Beltrán. México: Eds. Litoral, 1956.

Estrella en alto y nuevos poemas. Metáfora 4. México: Metáfora, 1956.

Para gozar tu paz. Textos amorosos. Ilustr. A. Beltrán. Cuadernos del Cocodrilo 3. México, 1957.

¡Mi pals, oh mi país! México, 1959.

Elegía de la policía montada. México, 1959.

Farsa trágica del presidente que quería una isla. México, 1961.

La raíz amarga. México, 1962.

El Tajín. Plaquetas del Pájaro Cascabel 3. México: Pájaro Cascabel, 1963

Barbas para desatar la lujuria. México, 1965.

Poemas. Selec. EH. Material de Lectura. Poesía Moderna 9. México: UNAM, 1968.

Poesía. 1935-1968. Serie del Volador. México: Mortiz, 1968.- 2a. ed. Lecturas Mexicanas. Segunda Serie 
54. México: Mortiz/SEP, 1986. Efraín Huerta. [Disco]. Presentación José Emilio Pacheco. Voz Viva de México. México: UNAM, 1969.2a. ed. 1982.

Poemas prohibidos y de amor. Mínima 62. México: Siglo XXI, 1973.- 5a. ed. 1987.

Los eróticos y otros poemas. Las Dos Orillas. México: Mortiz, 1974.

Poesía. Selec. Emilio Jorge Rodríguez. La Honda. La Habana: Casa de las Américas, 1975.

Circuito interior. México: Mortiz, 1977.

Antología poética. [Homenaje a EH]. Pról. Rafael Solana, Guanajuato, Gto.: Gob. del Edo./FEM, 1977.

50 poemínimos. México: Taller Martín Pescador, 1978.

Amor, patria mía. Ilustr. de J. Chávez Morado. México: Eds. de Cultura Popular, 1980.

Transa poética. Pról. y selec. EH. México: ERA, 1980.- 2a. ed. 1982.

Estampida de poemínimos. Libros del

Bicho 18. México: Premiá, 1980.- 2a. ed. 1981.

Juárez-Loreto y otros poemas. Cuadernos Mexicanos. México: SEP, 1982.

Efrain Huerta: absoluto amor. Presentación y Ed. Mónica Mansour. Pról. José Emilio Pacheco. Guanajuato, Gto.: Gob. del Edo., 1984. Efraín Huerta. Selec. y pról. Carlos Montemayor. Grandes Maestros Mexicanos 9. México: CREA/Terra Nova, 1985.

Poeminimos. Selec. y nota Francisco Paniagua. Lecturas Mínimas. Poesía. Toluca, Edo.Mex: Gob. del Edo., 1985.

Dispersión total. Comp. Thelma Nava y Raquel Huerta. Selec. Andrea y Eugenia Huerta. Ed. Mario del Va- lle. México: Eds. Papeles Privados, 1986.

Poesía completa. Ed. Martí Soler. Prol. David Huerta. Letras Mexicanas. México: FCE, 1988

\section{A.3. POEMAS EN ANTOLOGIAS $Y$ EN OTROS LIBROS}

Antología de la poesía mexicana. Ed. Manuel Maples Arce. México: Roma Poligráfica Tiberina, 1940. 404-408.

Poetas de México. Eds. Manuel González Ramírez y Rebeca Torres Ortega. México: América, 1945. 283286.

Lírica mexicana. Ed. Manuel Altolaguirre. México: El Ciervo Herido, 1950.

Antología de los 50 poetas. Ed. Jesús Arellano. México: Alatorre, 1952. 255-263.

La poesía mexicana moderna. Ed. Antonio Castro Leal. Letras Mexicanas, 12. México: FCE, 1953. 410415.

Poetas jovenes de México. Ed. Jesús Arellano. México: Libro-Mex, 1955. 26-30.

Palabra de hombre. [Poemas de EH, Jesús Arellano y Desiderio Macías Silva]. México: Moscos de Metáfora, 1959.

La poesía mexicana del siglo XX. Ed. Carlos Monsiváis. México: Empresas Editoriales, 1966. 558-573.Poesía mexicana II. 1915-1979. Clásicos de la Literatura Mexicana. México: Promexa, 1979. 239-260.

Poesía en movimiento. Ed. Octavio $\mathrm{Paz}$, et al. La Creación Literaria. Poesía. México: Siglo XXI, 1966. 241-254.

Poesía mexicana. Ed. Francisco Montes de Oca. México: Porrúa, 1968. 347-350. 
El sueño, el amor y la muerte. Ed. Jaime Labastida. México: IPN, 1969. 255-258.

"Palabras a Margarita Paz Paredes." [Poema introductorio]. M. Paz Paredes. Señales. México: Oasis, 1972.-2a. ed. 1979.

Antología general de la poesía mexicana. Siglos XVI-XX. Ed. Agustín del Saz. Libro Clásico. Madrid: Bruguera, 1972.

Museo poético. Ed. Salvador Elizondo. Textos Universitarios. México: UNAM, 1974. 280-286.

Antología de la poesía mexicana. Ed. Concepción García Moral. Madrid: Editora Nacional, 1975. 231-234.

Las cien peores poesías de autores famosos. Ed. Raúl Salinas Viniegras. México: Costa-Amic, 1975.

Reunión. Material de Lectura. Poesía Modema 20. México: UNAM, 1977. 23-26.

Crónica de la poesía mexicana. Ed. José Joaquín Blanco. Guadalajara, Jal.: INBA, 1977.- 3a. ed. México: Katún, 1981. 226-229.

La nueva poesía amorosa de América Latina. Eds. Saúl Ibargoyen y Jorge Boccanera. México: EDIMUSA, 1978. 205-207.

El Hijo Pródigo. Antología. Ed. Francisco Caudete. México: Siglo XXI, 1979. 94.

Ómnibus de poesía mexicana. Ed. Gabriel Zaid. 8a. ed. México: Siglo XXI, 1980. 593-594.

Un cuaderno de dibujo de Munik Sauret. Presentación en verso EH. México: Del Rehilete, 1980.

"Prólogos en verso." Prólogos. Cuadernos de Humanidades 19. México: UNAM, 1981.

Poesía erb́tica mexicana. Ed. Enrique Jaramillo Levi. México: Domés, 1982. I: 281-293.

Poesía rebelde de Latinoamérica. Eds.
Saúl Ibargoyen y Jorge Boccanera. México: EDIMUSA, 1983. 225227.

"A una cantante de rock." Crines. Lecturas de rock. México: Penélope, 1984. 13.

Antología de la poesía hispanoamericana. Ed. Juan Gustavo Cobo Borda. Tierra Firme. México: FCE, 1985. 146-149.

Vuelo de palabras. Ed. Juan Coronado. Poesía. México: Offset, 1986. 260-268.

Avantgarde und Revolution. Mexikanische Lyric von Lopez Velarde bis Octavio Paz. Ed. Klaus MeyerMinnemann. Germany: Vervuert, 1987. 158-163.

Paginas sobre la ciudad de México 1469-1987. Comp. Emmanuel Carballo y José Luis Martínez. México: Consejo de la Crónica de la Ciudad de México, 1988. 310$312+$.

En breve: Minimalism in Mexican Poetry 1900-1985. [Antología bilingüe inglés-español]. Trad. Enrique R. Lamadrid y E.A. Mares. Santa Fe, Nuevo Mexico: Toohs of Times Books, 1988. 36-39.

\section{B) HEMEROGRAFIA}

\section{B.1. ENSAYOS}

"Por una poesía de la juventud." [Los Contemporáneos]. Nac 9 mar. 1937: $1+$.

"La hora más hermosa." [Reseña. Carlos Pellicer, Hora de junio]. Diario del Sureste [Mérida, Yuc.] 30 mayo 1937.-B Bho 16 feb. 1992: 3.

“Tres libros españoles." [Reseñas. Antonio Sánchez Barbudo. Narraciones; Arturo Serrano Plaja. El hom- 
bre y el trabajo; Juan Gil Albert. Son hombres ignorados]. Taller dic. 1938: 60-63. - Ed. facs. I: 8891.

"Tramontar.", "Presencias." [José Bergamín]. Taller jul. 1939: 43-47; 54-55.- Ed. facs. I: 301-305; 312313.- Pro 8 feb. 1982: 46-47.

"Moraud y la pasión de la rapidez."

[Reseña. Paul Moraud. Viaje a México]. Romance 4 [México] 15 mar. 1940: 18.

"Hombre. Hamilton; Jelly-fish." [Senador norteamericano; Los peces en la literatura; Los cultivadores del hai-kai]. Pop 1o. abr. 1940: 3.

"Hombre. Los chivos jaculatorios." [La crítica de cine en Hoy; El general Cedillo alias 'Chivo jaculatorio'; Abelardo Rocas, embajador de Brasil]. Pop 3 abr. 1940: 3 t.

"Hombre. Un Cuauhtémoc tricolor."

[Reseña. José Vasconcelos, Breve historia de México; la Cervecería Cuauhtémoc]. Pop 4 abr. 1940: 3.

"Hombre. Nuevo Barón de MunchHausen." [Neville Mannerheim, político ruso]. Pop 6 abr. 1940: 3. "Hombre. La claque de Excélsior." [El asunto petrolero]. Pop 8 abr. 1940: 3.

"Hombre. Los abedules de Carelia." [La guerra mundial]. Pop 10 abr. 1940: 3.

"Hombre. Truculencias." [Continúa con el asunto del petróleo]. Pop 11 abr. 1940: 3 .

"Hombre. Nubes voladoras." [Almazanistas]. Pop 13 abr. 1940: 3.

"Hombre. ¡Oh, los polizones!" Pop 15 abr. 1940: 3.

"Hombre. Bertrand Russell y "Armillita'." Pop 17 abr. 1940: 3.

"Hombre. El plan de Monterrey." [A]mazanistas y sinarquistas]. Pop 18 abr. 1940: 3.

"Hombre. Sobre la levitación." [Cam- paña almazanista]. Pop 20 abr. 1940: 3.

"Hombre. Los males ultrajantes." [Congreso del Partido Acción Nacional]. Pop: 22 abr. 1940: 3; II, "Los nefebilatas." 24 abr. 1940: 3; III, [Según los ve El Universal]. 25 abr. 1940: 3.

"Hombre. Veinte pasos y pistola." [Críticas de El Universal a El Popular]. Pop 27 abr. 1940: 3.

"Hombre. Un millón de silencio."

[Ante la polémica propuesta a $\mathrm{El}$ Universal]. Pop 29 abr. 1940: 3.

"Hombre. Primero de mayo." [I a conmemoración; Italia frente a la gueпra]. Pop 10. mayo 1940: 3.

"Hombre. El hombre y el trabajo." Pop 4 mayo 1940: 3.

"Hombre. El contra-cordellazo." [Los

E.U. frente a Hitler]. Pop 6 mayo 1940: 3.

"Hombre. El jardín de los bobos." [Vendepatrias]. Pop 8 mayo 1940: 3.

"Hombre. Los budistas y la divina providencia." [La guerra; Comenta un editorial de Excélsior]. Pop 9 mayo 1940: 3.

"Hombre. El rapto de Europa. Silencios. De nuevo Trostky." [La guerra y el petróleo]. Pop 11 mayo 1940: 3.

"Hombre. Bersaglierismo." [El ascenso de Churchill]. Pop 13 mayo 1940: 3.

"Hombre. Almazán el inmóvil." Pop 15 mayo 1940: 3.

"Hombre. La amarga Francia." Pop 16 mayo 1940: 3.

"Hombre. El guadalupanismo de Almazán." Pop 18 mayo 1940: 3.

"Hombre. No iremos a la guerra. Mi capi Arias Barraza." Pop 20 mayo 1940: 3.

"Hombre. Desde San Francisco, California." [El petróleo]. Pop 22 mayo 1940: 3 . 
"Hombre. Sonetos a la virgen." [Almazán y la guerra mundial]. Pop 23 mayo 1940: 3.

"Hombre. Isla mi isla." [Inglaterra en la guerra]. Pop 25 mayo 1940: 3. "Hombre. Las balas frías. A las trece." Pop 27 mayo 1940: 3.

"Hombre. Vieja raposa, avarienta."

[La guerra mundial]. Pop 29 mayo 1940: 3.

"Hombre. Civismo y cinismo." [Manuel Gómez Morín; Ludwing y el Duce en la guerra]. Pop 30 mayo 1940: 3.

"Bajo las palmeras de la crítica." [Reseña. Xavier Villaurrutia, Textos y pretextos]. Romance 11 [México] 1o. jul. 1940: 18.

"Organización del sarcasmo." [Reseña. José Herrera Petere, Niebla de cuernos]. Taller jul.-ago. 1940: 7173- - Ed. facs. II: 401-403.

"La Revolución y la poesía popular." Nac 24 nov. 1940.

"Hombre." [Parodia sobre el año nuevo]. Pop 1o. ene. 1941: 5.

"Hombre. Mexican-Arios. Chaplin y la justicia humana." [Propaganda política]. Pop 2 ene. 1941: 5.

"Hombre. Ascenso y posterga. Salazar-Goebbels." [y el general Rubén García]. Pop 3 ene. 1941: 5.

"Hombre. Una opinión de calidad sobre el caso Prestes." [Derechos humanos en Brasil]. Pop 4 ene. 1941: 5.

"Hombre. Coincidencia." [La crítica periodística]. Pop 5 ene. 1941: 5. "Hombre. Bergonzzoti." [General italiano]. Pop 7 ene. 1941: 5. "Hombre. El tranvía 830." [Compañía de Tranvías de México]. Pop 8 ene. 1941: 5.

"Hombre. Un atentado más. La pesadilla de Morones." [Comenta un discurso de éste]. Pop 9 ene. 1941: 5.
"Hombre. Bombas sobre Tlalnepantla." [Desalojos]. Pop 10 ene. 1941: 5.

"Hombre. Prietos y negros." [Campaña de Excélsior en contra de los refugiados españoles]. Pop 11 ene. 1941: 5.

"Hombre. Argentina y la URSS. Católicos y fascistas." Pop 13 ene. 1941: 5.

"Hombre. ¿Piedad o crueldad?" Pop 14 ene. 1941: 5.

"Hombre. León enjaulado." [Propaganda antifascista a cargo de Adolfo León Ossorio]. Pop 16 ene. 1941: 5.

“Hombre. ¡Píquen]e!” [El transporte urbano]. Pop 17 ene. 1941: 5.

"Hombre. La invación de los marcianos." [Orson Welles y su película]. Pop 18 ene. 1941: 5.

"Hombre. Habrá barcos." [Para los refugiados españoles]. Pop 20 ene. 1941: 5 .

"Hombre. Elogio del petate." [Cita una nota roja curiosa]. Pop 21 ene. 1941: 5 .

"Hombre. Tres voces de México." [Cartas de Enrique González Martínez, Carlos Pellicer y Gabriel Fernández Ledesma en apoyo a Prestes]. Pop 22 ene. 1941: 5.

"Hombre. Los de la quinta. Prestes."

[Armamentismo; Poema de Ma. Luisa Carnelli]. Pop 23 ene. 1941: 5.

"Hombre. ¿Paz en España?" Pop 24 ene. 1941: 5.

"Hombre. Refranes." Pop 25 ene. 1941: 5.

"Hombre. Películas y jamón serrano."

[Carta de un lector sobre los refugiados]. Pop 27 ene. 1941: 5.

"Hombre. Nuestros pobres." [De

América Latina]. Pop 28 ene.

1941: 5.

"Hombre. Bregas, frescuras y otras 
cosas." [Partido Acción Nacional]. Pop 29 ene. 1941: 5.

"Hombre. Benita." [Frag. Benita Galeana. Benita.] Pop 30 ene. 1941: 5.

"Hombre. La hora oficial y la gripa." [El ahorro de energía eléctrica]. Pop 31 ene. 1941: 5.

"Una antología de forcejeos." [Reseña. Manuel Maples Arce. Antología de la poesía mexicana moderna], "La nube exacta y el reloj nublado." [Reseña. Luis Cardoza y Aragón, La nube y el reloj]. Taller ene.-feb. 1941: 68-71.- Ed. facs. II: 510-513.

"Hombre. A buen hambre. Desagravio a Mussolini." [El hambre en París]. Pop 1o. feb. 1941: 5.

"Hombre. Así son." [Rev. Ser, de los falangistas españoles]. Pop 3 feb. 1941: 5.

"Hombre. Sinarquistas." Pop 4 feb. 1941: 5.

"Hombre. Con pescado y sin sangre." [La pobreza]. Pop 5 feb. 1941: 5.

"Hombre. Sobre la Laguna." [La comarca lagunera]. Pop 6 feb. 1941: 5.

"Hombre. Frente a Denver. ¿Hoy como ayer? Ser mejor." [Religion y economía]. Pop 7 feb. 1941: 5.

"Hombre. ¿Quién derrotará a Hitler?" Pop 8 feb. 1941: 5.

"Hombre. Palabras de Bernard Shaw." Pop 10 feb. 1941: 5.

"Hombre. Cuando se pelean las comadres." [Los proyectos de Almazán]. Pop 11 feb. 1941: 5.

"Hogmbre. México abre sus brazos." [A los refugiados]. Pop 12 feb. 1941: 5 .

"Hombre. La vida cara." [Alude a un reportaje sobre la pobreza]. Pop 13 feb. 1941: 5.

“Hombre. Fábula vieja." Pop 15 feb. 1941: 5.
"Hombre. Chapultepec." Pop 18 feb. 1941: 5.

"Hombre. Espías." Pop 21 feb. 1941: 5.

"Hombre. Lo que no se dice." [Despidos masivos en Excélsior]. Pop 22 feb. 1941: 5 .

"Hombre. Antiguas máscaras." [Periódicos y otras notas]. Pop 24 feb. 1941: 5 .

"Hombre. La señora que no sabía que hay guerra." [Elizabeth Hamshire, inglesa]. Pop 25 feb. 1941: 5-6.

"Hombre. Una lista insuficiente. Sinarquistas y con túnica." Pop 26 feb. 1941: 5 .

"Hombre. Un enemigo público: la mugrola." [Carta de David Arrillaga Meneses]. Pop 27 feb. 1941: 5.

"La huella de sangre." [Garrido Canabal]. Asi [México]: 3, 10 mayo 1941.

"La locura en acción." Así [México]: 17, 24 mayo 1941.

"La matanza y el terror garridista en Tenosique." Así [México] 28 jun. 1941.

"Hombre. Predicciones de la señora María Villasclaras." Pop 1o. ene. 1942: 5.

"Hombre. La quinta columna en Filipinas. ¿Hay un racismo antinazi?" Pop 3 ene. 1942: 5.

"Hombre. En el café." [División en el Partido Acción Nacional].' Pop 5 ene. 1942: 5.

"Hombre. ¿Contra quién lucha $\mathrm{Hi}$ tler?" Pop 6 ene. 1942: 5.

"Hombre. Lo dice la biblia. Los EU entraron a la guerra." Pop 9 ene. 1942: 5.

"Hombre. Mi lucha y su lucha." [Reseña. Hitler. Mi lucha]. Pop 10 ene. 1942: 5.

"Hombre. Pies de barro." [Alemania, un auténtico gigante de hierro]. Pop 13 ene. 1942: 5. 
"Hombre. Serge y compañía." [Víctor Serge, Julián Gorkin y Pivert, editorialistas]. Pop 14 ene. 1942: 5.

"Hombre. Barba Jacob." Pop 15 ene. 1942: 5.

"Hombre. Premisas sobre el tango. Clemente López Trujillo, habitante ael mayab." Pop 16 ene. 1942: 5.

"Hombre. Contradicciones seudo-filosóficas." [Muerte e ironía]. Pop 20 ene. 1942: 5.

"Hombre. Lenin en octubre." Pop 21 ene. 1942: 5.

"Hombre. Un siglo de militancia." [Serge y compañía, quintacolumnistas de El Universal]. Pop 22 ene. 1942: 5.

"Hombre. Es o no apache Víctor Serge." [Enemigo de gambusinos norteamericanos y mexicanos]. Pop 23 ene. 1942: 5.

"Hombre. Un nuevo purgatorio." [Recaptura de la ciudad de Smolensk]. Pop 27 ene. 1942: 5.

"Hombre. Respuesta a Julían Gorkin." Pop 28 ene. 1942: 5.

"Hombre. El complejo de Smolensk." [Plaza estratégica en la guerra]. Pop 29 ene. 1942: 5.

"Hombre. Las planillas y Díaz Lombardo." [Líder de la Alianza de Camioneros]. Pop 30 ene. 1942: 5. "Guía de malogrados." [Frag]. Rueca 3 verano. 1942: 12-15.- Ed. facs. I: $156-159$.

"Una poesía sin mitos." $L M 15$ nov. 1942: 8. - Ed. facs. III: 280.

"Libros de poesía. Estudios sobre poetas venezolanos de Vanegas Filardo." [Reseña]. LM 15 mar. 1943: 3.- Ed. facs. IV: 33.

"Close up." [Exhibición vs. producción; Escritores-guionistas: José Revueltas y Edmundo Báez]. RevMC 6 abr. 1947: 15.

"Atardeceres de la feria." [Del libro]. RevMC 4 mayo 1947: 15.
"Close up." [Altos costos de producción]. RevMC 11 mayo 1947: 15.

"Close up." [Relaciones laborales; Los escritores de cine: Mariano Azuela, Jesús Goytortúa Santos, Rafael F. Muñoz, Francisco Rojas González, José Revueltas y Antonio Magaña Esquivel]. RevMC 18 mayo 1947: 15.

"Close up." [La publicidad]. RevMC 8 jun. 1947: 15.

“Close up." [La lucha de Adolfo Fernández Bustamante; El parasitismo en el cine]. RevMC 15 jun. 1947: 15.

"Close up." [El reparto]. RevMC 29 jun. 1947: 15.

"Close up." [La recuperación]. RevMC 6 jul. 1947: 15.

"Close up." [Adaptadores, argumentistas, dialoguistas y la mala calidad del cine]. RevMC 12 jul. 1947: 15. "Close up." [Reseña. Carol Reed. Larga es la noche]. RevMC 19 jul. 1947: 15.

"Close up." [Figueroa-Fernández]. RevMC 26 jul. 1947: 15.

"María Izquierdo y nuestra tierra.", "Close up." [La imagen de las estrellas]. RevMC 3 ago. 1947: 1516.

"Close up." [Banco Cinematográfico]. RevMC 10 ago. 1947: 15

"Close up." [Los actores no se administran]. RevMC 17 ago. 1947: 15

"Close up." [Censura]. RevMC 24 ago. 1947: 15.

"Close up." [Cine de mala calidad]. RevMC 31 ago. 1947: 15.

“Close up." [Reseña. Emilio Fernández. La perla; Alejandro Galindo]. RevMC 14 sep. 1947: 15.

"Close up." [Reseña. Ismael Rodríguez. Los tres García]. RevMC 21 sep. 1947: 14.

"Close up." [La crítica]. RevMC 28 sep. 1947: 14. 
"Close up." [María Félix y Agustín Lara]. RevMC 5 oct. 1947: 15.

"Close up." [Isabela Corona]. RevMC 12 oct. 1947: 13.

"Don Quijote y el cine." RevMC 19 oct. 1947: 15.

"Close up." [Películas sobre la conquista]. RevMC 9 nov. 1947: 14.

"Close up." [Dolores del Río]. RevMC 30 nov. 1947: 15.

"Close up." [Edmundo Báez, argumentista]. RevMC 14 dic. 1947: 15.

"Close up." [José Espert Arcos, publicista]. RevMC 18 ene. 1948: 15.

"Close up." [Reunión de Cinematografistas]. RevMC 1o. feb. 1948: 15.

"Close up. El cine de Alejandro Galindo." RevMC 8 feb. 1948: 15.

"Close up." [Escasez de película virgenl. RevMC 15 feb. 1948: 15.

"Close up. Macbeth, el último film de Orson Welles." [Reseña]. RevMC 29 feb. 1948: 15.

“Close up. El cine de Emilio 'Indio' Fernández." RevMC 7 mar. 1948: 15.

"Close up." [Los premios]. RevMC 28 mar. 1948: 15.

"Close up." [El cine de $16 \mathrm{~mm}$ ]. RevMC 4 abr. 1948: 15.

"Close up." [Reseña. Emilio Fernández. Maclovia]. RevMC 18 abr. 1948: 15.

"Close up." [Las actrices]. RevMC 2 mayo 1948: 15.

"Close up. El cine de Ismael Rodríguez." RevMC 9 mayo 1948: 15.

"Close up." [Asociación Naciona] de Actores]. RevMC 30 mayo 1948: 15.

"Close up." [Técnica cinematográfica]. RevMC 6 jun. 1948: 15.

"Close up." [Rosa de Castaño acusa al 'Indio' Femández de plagio]. RevMC 13 jun. 1948: 15.
"Close up." [Nuevo comité ejecutivo del Sindicato de Trabajadores de la Producción Cinematográfica]. RevMC 4 jul. 1948: 15.

"Close up. El ingeniero Salvador Toscano, precursor del cine en México." RevMC 10 oct. 1948: 15.

"Close up. El cine del 'Indio' Fernández, Maclovia. y Flor sitvestre." RevMC 17 oct. 1948: 15.

"Close up. El cine de Julio Bracho." [Reseña. Rosenda, basada en la novela de José Rubén Romero]. RevMC 14 nov. 1948: 15.

"Radar filmico." [Grovas Producciones]. Nac 3 dic. 1948: 1, 2a. Sec.

"Radar filmico." [Conferencia de Adolfo Fernández Bustamante]. Nac 4 dic. 1948: 1, 2a. Sec.

"Close up. El cine de Ismael Rodríguez." RevMC 5 dic. 1948: 15.

"Radar fílmico." [Reseña. Uni tranvía llamado deseo, basada en la obra de T. Williams]. Nac 8 dic. 1948: 1, 2a. Sec.

"Close up. Hamlet. Una fecha para la historia futura del teatro cinematográfico." RevMC 26 dic. 1948: 15.

"Close up. El cine y el paisaje en México." RevMC 2 ene. 1949: 15.

"Close up. Las dos primeras películas mexicanas habladas y musicadas." RevMC 13 mar. 1949: 15.

"Close up. Alejandro Galindo, director impar." RevMC 20 mar. 1949: 15.

"Close up. Río escondido, premio 1948." [Reseña. Emilio Fernández]. RevMC 10 abr. 1949: 15.

"Close up." [Reseña. La vorágine, basada en la obra de José Eustasio Rivera]. RevMC 24 abr. 1949: 15.

"Close up. La sirena." [Sinopsis y comentarios]. RevMC 3 jul. 1949: 15. "Close up. Perfil de José Revueltas." RevMC 11 sep. 1949: 15.

"Close up. Recuerdo de Blanca Estela 
Pavón." RevMC 23 oct. 1949: 15. “Close up. La Revolución a través del cine." RevMC 20 nov. 1949: 15.

"Close up. Las tribulaciones de Roberto Cañedo." RevMC 4 dic. 1949: 15.

"Close up. Defensa de Rubén Rojo; Fernando Soler el mejor actor." RevMC 11 dic. 1949: 15.

"Close up. Más en torno a La negra angustias, segunda película de Matilde Landeta." [Basada en la novela de Francisco Rojas González]. RevMC 29 ene. 1950: 15.

"Close up. Programa de Crédito Cinematográfico Mexicano." RevMC 5 feb. 1950: 15.

"Close up." [El realismo en el cine]. RevMC 26 feb. 1950: 15.

“Close up. Isabella, la grande." [Isabela Corona]. RevMC 9 abr. 1950: 15.

"Close up. El Ariel y sus favoritos." RevMC 16 abr. 1950: 15.

"Close up. Las joyas del pecado." [Basada en cuentos de Guy de Maupassant]. RevMC 30 abr. 1950: 15.

"Close up." [Maneras de hacer cine]. RevMC 14 mayo 1950: 15.

"El vapuleado cuadrante." [Reseña. José Revueltas. El cuadrante de la soledad] Nos 27 mayo 1950.CuM 7 feb. 1990: 37.

"Close up." [Financiamiento al cine]. RevMC 28 mayo 1950:15.

"Close up. Los diez de Hollywood." [La censura]. RevMC 25 jun. 1950: 15.

"Close up. Una actriz: Miroslava; un actor: Emesto Alonso." RevMC 16 jul. 1950:15.

"Close up." [Las estrellas de radio, al cine]. RevMC 13 ago. 1950: 15.

"Close up. Alrededor de Los olvidados." [Reseña. Buñuel]. RevMC 17 sep. 1950: 15.
“Close up. ¿Qué sabe Europa del cine mexicano?" RevMC 8 oct. 1950: 15.

"Close up. Retomo de una olvidada." [Reseña. Buñuel. Los olvidados]. RevMC 5 nov. 1950: 15.

"Close up. Un film sobre la Revolución. Emilio Femández. Un día de vida." RevMC 19 nov. 1950: 15.

"Close up. Revelación de Rosaura Revueltas." RevMC 10 dic. 1950: 15.

"Close up. Abundancia y pobreza de directores." RevMC 24 dic. 1950: 15.

"Close up. Ir y venir de Irma Torres." RevMC 31 dic. 1950: 15.

"Close up. El cine y Xavier Villaurrutia." RevMC 7 ene. 1951: 10.

"Close up. Aforismos y definiciones." [Pequeña antología]. $\operatorname{RevMC} 21$ ene. 1951: 15.

“Close up. ¡Flaubert: toma tu fusil! Carta de Emma Bovary a Jennifer Jones." RevMC 28 ene. 1951: 15.

"Close up. Breve reseña de los cines en México." RevMC 4 feb. 1951: 15.

"Close up. La organización de la cinematografia checoslovaca." RevMC 11 feb 1951: 15.

"Close up. La hora cero de Pedro Infante." RevMC 15 abr. 1951: 13.

"Close up." [Reseña. Buñuel. Los olvidados]. RevMC 29 abr. 1951: 14. "Close up. Alma Delia Fuentes, la muchacha de oro." RevMC 6 mayo 1951: 14.

“Close up. Sexto Festival Internacional de Películas, en Checoslovaquia." RevMC 13 mayo 1951: 14.

"Close up. Sarita Montiel." RevMC 20 mayo 1951: 14.

"Close up. La Escuela Superior de Cinematografía de Lodz." RevMC: 27 mayo 1951: 14; II, 3 jun. 1951: 14.

"Close up. María Félix, tres Arieles." 
RevMC 15 jul. 1951: 14.

"Close up." [Ley de la Industria Cinematográfica]. RevMC 19 ago. 1951: 14.

“Close up." [Emilio 'Indio' Femández]. RevMC 26 ago. 1951: 14.

"Close up." [La producción, detenida]. RevMC 9 sep. 1951:14.

"Ocaranza es un demonio de poeta amalditadamente romántico." Nac 7 oct. 1951.- Centavo 80. jun.jul. 1969: 10.

"Close up. Serra Rojas, múltiple y cordial" [En el Banco Cinematográfico]. RevMC 14 oct. 1951: 14.

“Close up. ¡Académicos!” [Francisco Monterde reasume la presidencia de la Academia Mexicana de Artes y Ciencias Cinematográficas]. RevMC 21 oct. 1951: 14.

"Close up." [EI cine mexicano en crisis]. RevMC 18 nov. 1951: 14.

"Close up." [Semana Nacional Cinematográfica]. RevMC: I, 2 dic. 1951: 14; II, 9 dic. 1951: 14t.

"Close up." [Premios de la Academia]. $\operatorname{RevMC} 6$ ene. 1952: 14.

"Close up." [María Félix]. RevMC 13 ene. 1952: 14.

"Close up." [Películas de 1951]. RevMC 20 ene. 1952: 14.

"Close up." [Buñuel. Los olvidados y Eisenstein]. RevMC 2 mar. 1952: 14.

"Close up." [Cuadros de actores]. RevMC 9 mar. 1952: 14.

"Close up." [El cine mexicano conocido en el extranjero por la mancuerna Fernández-Figueroa]. RevMC 6 jul. 1952: 13.

"Close up." [Los directores]. RevMC 27 jul. 1952: 13.

"Close up." [El ambiente cinematográfico]. RevMC 3 ago. 1952: 13.

"Close up." [Las estrellas]. RevMC 10 ago. 1952: 13.

"Close up." [Sube el precio de entrada a los cines]. $\operatorname{Rev} M C 17$ ago. 1952: 13.

"El maestro Mancisidor." MC 2 sep. 1956: 3.

"Dos décados de radio, televisión, teatro y cine." [Su significación histórica]. Nos 30 abr. 1964.

"Ases y estrellas. María la del amor y el sexo." [María Félix]. Nos 15 jun. 1964.

"Ases y estrellas. Lo popular: Cantinflas." Nos 28 sep. 1964.

"Ases y estrellas." [Reseña. Daniel Castañeda. Balance de Agustín Lara]. Nos 16 ago. 1965.

"Salvador Toscano o de la sabiduría." Día 6 oct. 1965.

"Ases y estrellas. Nuestra Revolución y el cine nacional." Nos 15 nov. 1965.

"La cerámica erótica de Víctor." Ovaciones, Supl. 31 ago. 1966: 2.

"Ases y estrellas." [Reseña. José Bolaños. La soldadera]. Nos 19 ago. 1967.

"Encuesta sobre Ramón López Velarde." GI 10 ago. 1969: 4.

"Siete sobre la poesía." Rehilete 29 [México] dic. 1969: 5.

"Crestomanía ingenua. Pesadillas y cuentos de hadas." $H C: 1,7$ feb. 1971: 2-3; II, 14 feb. 1971: 2-3.

"Sobre nuestro cuento." $H C 25$ abr. 1971: 2-3.

"Me resucitan o me dejan como estaba." [En el Diccionario Porrúa lo dan por muerto en 1968]. $H C: 4$ jul. 1971: 5; II, "Funerales Porrúa me dio la puntilla." 17 oct. 1971: 2.- "Necrofilia. El Diccionario Porrúa insiste en darme por muerto." GI 13 feb. 1977: 21; II, 20 feb. 1977: 19.

"Sobre nuestro ensayo." HC 14 nov. 1971: 2-4.

"En tomo a Poesía joven de Panamá." HC 26 dic. 1971: 8-9. 
"Antonio Machado: poeta de sí mismo." CLE 16. 1971: 20-22.- GI 27 jul. 1975: 3.

"Deslindes. Destilando veneno." [Los pleitos entre autores e impresores]. DdeMéx 9 mar. 1972: 2.

"Deslindes.Universidad." [RUMex]. DdeMéx 23 mar. 1972: 2.

"Deslindes.Versos musicados." DdeMéx 25 mar. 1972: 2.

"Deslindes. 62 fieras líricas." [Premio Poesía Aguascalientes]. DdeMéx 27 mar. 1972: 2.

“Deslindes. Espejutlandia." DdeMéx 1o. abr. 1972: 2.

"Deslindes. Paraíso infantil." DdeMéx 3 abr. 1972: 2.

"Deslindes, El viejo Sadoul." [Crítico de cine]. DdeMéx 4 abr. 1972: 2.

"Deslindes. Lo más cursi." DdeMéx 6 abr. 1972: 2.

"Deslindes. 58 documentos." [Reseña. José E. Iturriaga, Pensamiento político y administrativo del presidente Juárez]. DdeMéx 7 abr. 1972: 2.

"Deslindes. Las adversidades." [más de José E. Iturriaga]. DdeMéx 8 abr. 1972: 2.

"Deslindes. ¿Seria o feria?" [¿Cómo es una ciudad?] DdeMéx 10 abr. 1972: 2.

"Deslindes, Sumamente pobre." [Anécdota sobre Ramón de Valle Inclán y su libro La pipa de kif]. DdeMéx 11 abr. 1972: 2.

"Deslindes. Charles Dickens." DdeMéx 13 abr. 1972: 2.

"Deslirides. El auto, asesino..." [De la ciudad]. DdeMéx 15 abr. 1972: 2.

"Deslindes. Los veleidosos." [Chaplin]. DdeMéx 17 abr. 1972: 2.

"Deslindes. La guantanamera." [Variaciones en su letra y música]. DdeMéx 20 abr. 1972: 2.

"Deslindes. Cuestión de orejas." DdeMéx 22 abr. 1972: 2.
"Destindes. Cardenal-Retamar." [Reseña. Ernesto Cardenal. En Cuba]. DdeMéx 24 abr. 1972: 2.

"Deslindes. Cardenal-Guillén." [Anécdota sobre Nicolás Guillén]. DdeMéx 25 abr. 1972: 2.

"Deslindes. Prima ballerina." [Alicia Alonso]. DdeMéx 26 abr. 1972: 2.

"Deslindes. Asedio a Juárez." [Cita un texto de Antonio Acevedo Escobedo]. DdeMéx 29 abr. 1972: 2.

"Deslindes. Montes de Oca." [Marco Antonio]. DdeMéx 8 mayo 1972: 2.

“Deslindes. Canción-consumo." DdeMéx 10. juil. 1972: 2.

"Deslindes. El zorzal criollo." [Gardel a 37 años de su muerte]. DdeMéx 3 jul. 1972: 2.

"Deslindes. Calamidades." [La vanidad de los escritores]. DdeMéx 5 jul. 1972: 2.

"Deslindes. El mar, el mar..." [Tema literario]. DdeMéx 7 jul. 1972: 2.

"Deslindes. Receta de mujer." [Vinicius de Moraes]. DdeMéx 8 jul. 1972: 2.

"Deslindes. Nicolás Guillén." DdeMéx 10 jul. 1972: 2.

"Deslindes. Sucedió en Texas." [Anécdotas]. DdeMéx 11 jul. 1972: 2.

"Deslindes. ¡Ese don Porfirio!" [Díaz]. DdeMéx 15 jul. 1972: 2.

"Deslindes. La noche de Juárez." DdeMéx 17 jul. 1972: 2.

"Deslindes. Juárez trabajaba..." DdeMéx 18 jul. 1972: 2.

"Deslindes. Juárez y Martí." DdeMéx 19 jul. 1972: 2.

"Deslindes. Juárez en Panamá." DdeMéx 20 jul. 1972: 2.

"Deslindes. La prensa adversa." [A Juárez]. DdeMéx 21 jul. 1972: 2. "Deslindes. Los ardidos." [Premios literarios]. DdeMéx 29 jul. 1972: 2. "Deslindes. La furia del libro." [Feria 
del pasaje Zócalo-Pino Suárez]. DdeMéx 31 jul. 1972: 2.

"Deslindes. Monterroso." DdeMéx 19 sep. 1972: 2.

"Deslindes. El poeta suicida." [Manuel Acuña]. DdeMéx 20 sep. 1972: 2.

"Deslindes. Otro Woolworth." [Polanco]. DdeMéx 2 oct. 1972: 2.

"Deslindes. Toda una maestra." [Ma. del Carmen Ruiz Castañeda]. DdeMéx 5 oct. 1972: 2.

"Deslindes. La musa popular." [En la época juarista, estudio de Ma. del Carmen Ruiz Castañeda e Isabel Vázquez Valle]. DdeMéx 6 oct. 1972: 2.

"Deslindes. El influyentazo." DdeMéx 9 oct. 1972: 2.

"Deslindes. Otra suicida." [Alejandra Pizanik]. DdeMéx 10 oct. 1972: 2. "Deslindes. Poelectrones." [Reseña. Jesús Arellano. Canto del gallo]. DdeMéx 11 oct. 1972: 2.

"Deslindes. Un argentino loco." [Astor Piazzola y el tango]. DdeMéx 12 oct. 1972: 2 .

"Deslindes. Argentino menos loco." [Borges]. DdeMéx 13 oct. 1972: 2. "Deslindes. Carta chicana." [Rev. Liberación]. DdeMéx 14 oct. 1972: 2.

"Deslindes. Las orquídeas." DdeMéx. 16 oct. 1972: 2.

"Deslindes. La vorágine." [Eds. y críticas a la obra de José Eustasio Rivera]. DdeMéx 17 oct. 1972: 2.

"Deslindes. La gran ironía." [Cita a Fernando Rivas, que habla de Cuba]. DdeMéx: 19 oct. 1972: 2; II, "Cocodrilandia." 20 oct. 1972: 2.

"Deslindes. Rulfo otra vez." DdeMéx 21 oct. 1972: 2.

"Deslindes. El acueducto." [De la ciudad de Querétaro]. DdeMéx 23 oct. 1972: 2.
"Deslindes. Los esclavos." [Discriminación racial en Sudafrica]. DdeMéx: 24 oct. 1972:. 2; II, "Cienciaficción." 25 oct. 1972: 2.

"Deslindes. La guitarra." [Vinicius de Moraes y la música]. DdeMéx 26 oct. 1972: 2.

"Deslindes. La desesperanza." [Estudios sobre Juárez]. DdeMéx 27 oct. 1972: 2.

"Deslindes. La momiza." DdeMéx 28 oct. 1972: 2.

"Deslindes. Concurso Casa." [Casa de las Américas]. DdeMéx 30 oct. 1972: 2.

"Deslindes. Comentario crítico a La isla de los hombres solos" [José León Sánchez]. DdeMéx 30 oct. 1972-10 ene. 1973: 2, 2a. Sec.

"Deslindes. Piazzola, el necio." DdeMéx 31 oct. 1972: 2.

"Deslindes. G.H. Hudson." [Joaquín de Montezuma de Carvalho, "El mundo maravilloso de Guillermo Enrique Hudson."]. DdeMéx 2 ene. 1973: 2.

“Deslindes. Sobre grafografía." [Reseña. Salvador Elizondo, El grafógrafo]. DdeMéx 3 ene. 1973: 2.

"Deslindes. Cuentos editados por el Instituto Nacional de la Juventud Mexicana." DdeMéx 4 ene. 1973: 2.

"Deslindes. Memoraciones." [Hiroshima]. DdeMéx 5 ene. 1973: 2.

"Deslindes. La fuga increíble." DdeMéx 6 ene. 1973: 2.

"Deslindes. Comercial agresivo." DdeMéx 8 ene. 1973: 2.

"Deslindes. Siempre Alicia." [Lewis Carrol]. DdeMéx 9 ene. 1973: 2.

"Deslindes. Una famosa carta." [La fotografía]. DdeMéx: 10 ene. 1973: 2; II, 11 ene. 1973: 2.

"Deslindes. John Reed." DdeMéx 12 ene. 1973: 2.

“Deslindes. Víctor Estrada." [Pintor]. 
DdeMéx 13 ene. 1973: 2.

"Deslindes. Cosas de la televisión." [Manipulación informativa]. DdeMéx 15 ene. 1973: 2.

"Deslindes. Sobre Managua." DdeMéx 16 ene. 1973: 2.

"Deslindes. Charla y dicción." DdeMéx 17 ene. 1973: 2.

"Deslindes. Ciegos, otra vez." [Tema literario]. DdeMéx 18 ene. 1973: 2. "Deslindes. Amor definido." [En la literatura]. DdeMéx 19 ene. 1973: 2. "Deslindes. Amor poderoso." [En la literatura]. Rev.MC 20 ene. 1973: 2.

"Deslindes. Más conjeturas." [Reseña. Salvador Elizondo. El grafógrafo]. DdeMéx 23 ene. 1973: 2.

"Deslindes. Aguascalientes." [Premio de Poesía]. Rev.MC 24 ene. 1973: 2.

"Deslindes. Códices-suspenso." [Reseña. María Sten. La extraordinaria historia de los códices mexicanos].

DdeMéx 25 ene. 1973: 2.

"Deslindes. Himnos regionales." [ $\mathrm{Au}-$ tores de sus letras y músicas]. DdeMéx 26 ene. 1973: 2.

"Deslindes. Calendariazo: Lotería Nacional." [En su nuevo edificio]. DdeMéx 29 ene. 1973: 2.

"Deslindes. El obispo." [Méndez Arceo]. DdeMéx 30 ene. 1973: 2.

"Deslindes. La cursilería." DdeMéx 31 ene. 1973: 2.

"Poderío de Pablo." [ Neruda]. $R U$ Mex 27.9 mayo 1973: 31-36.Día [Supl. de Aniversario] 26 jun. 1974: 22-24.

"De poetas acasillados en un país anti-libresco: Salvador Novo y Ermilo Abreu Gómez." CuM 6 ago. 1975: ii-v.

Libros. [Susan Sontag; La historieta Fantomas]. GI 31 ago. 1975: 6. Libros. [Ezra Pound]. GI 7 sep. 1975: 3.
Libros. [Fábula martiana; Raymundo Lazo. José Martí: hombre apostólico y escritor]. GI 14 sep. 1975: 5.

Libros. [Neruda hace dos años]. GI 21 sep. 1975: 5 .

Libros. [Los plagiarios]. GI 28 sep. 1975: 5.

Libros. [Enrique Marroquín. La contracultura como protesta]. GI 5 oct. 1975: 5.

Libros. [Iosé Gorostiza. Muerte sin fin]. GI 12 oct. 1975: 5.

Libros. [Poetas y políticos; Octavio G. Barreda y Manuel Durán traductores de S.J. Perse]. GI 19 oct. 1975: 3.

Libros. [Los mitos. Tarzán de los monos]. GI 26 oct. 1975: 5.

"Eugenio Montale, un poeta de la dignidad." GI 2 nov. 1975: 2

Libros. [Ray Bradbury. El hombre ilustrado; Margaret Randall]. Gl 9 nov. 1975: 5.

Libros. [Tito Monterroso otra vez]. GI 16 nov. 1975: 5.

Libros. [Alejo Carpentier, gran clásico moderno]. GI 23 nov. 1975: 6-7.

Libros. [Citas sobre las ciudades]. GI 30 nov. 1975: 5.

Libros. [Margaret Randall ¿cuántos libros?] Gl 7 dic. 1975: 5.

Libros. [Jaime Labastida. Obsesiones con un tema obligado; Otto Raúl González; Eds. del Instituto Nacional de la Juventud Mexicana]. GI 14 dic. 1975: 5.

Libros. [El futbol]. GI 21 dic. 1975: 5 Libros. [Parménides García Saldaña. Mediodía; Poesía joven de Colombia]. GI 28 dic. 1975: 5.

Libros. [Gustavo Barrera. Textos; José de Alba; Marti; La Univ. de S.L.P.]. GI 4 ene. 1976: 5.

Libros. [J. Joyce. Obra en marcha; Carlette Tibon. Los tatarabuelos; Arturo Azuela. Un tal José Salo- 
mé; Eraclio Zepeda, Premio de Cuento S.L.P.] GI 11 ene. 1976: 5. Libros. [Jesús Arellano. El canto del gallo; Anécdotas de caballos]. GI 18 ene. 1976: 5.

Libros. [Concha Lagos, española; Rev. Alaluz; El tangol. GI 25 ene. 1976: 5.

"Deslindes - sobre Roque Dalton." CasA 94. ene.-feb. 1976: 39-41.

Libros. [Edmundo Desnoes. Memorias del subdesarrollo; El tango; Marianito Mores]. GI 1o. feb. 1976: 5.

Libros. [Paulina Madeiros. Felisberto Hernández y yo; Rubén Bonifaz Nuño, clasicista; Joyce]. GI 8 feb. 1976: 5.

Libros. [La música y el amor; Corridos y tangos: María Grever]. GI 15 feb. 1976: 5 .

Libros. [Cipriano Campos Alatorre. Los fusilados; Los corridos mexicanos; Juan Pascoe, tipógrafo; Miguel N. Lira, editor; Juan José Arreola]. GI 22 feb. 1976: 5.

Libros. [Francisco Santiago Cruz. La conquista florida; Alejandro Avilés. Los claros días; Emesto Cardenal, escultor y poeta]. GI $29 \mathrm{feb}$. 1976: 5.

Libros. [Manuel González Calzada. México vasco; Ricardo Palma. Tradiciones en salsa verde; Los vascos y el futbol; Leticia Ocharán, pintora]. GI 7 mar. 1976: 7.

Libros. [Antonio Acevedo Escobedo.

En la ola del tiempo; Vicente $\mathrm{T}$. Mendoza. Cien romances escogidos; Borges; Carlos Isla]. GI 14 mar. 1976: 3.

Libros. [Joyce]. GI 18 abr. 1976: 5. "Revueltas: la imaginación." GI 25 abr. 1976: 3.

Libros. [J. Joyce. Ulises; Olga Arias. El tapiz de Penélope; La castidad; Las traducciones]. GI 2 mayo 1976: 9.
Libros. [D.L. Pitty. Realidades y fantasías; Diez años de la editorial Siglo XXI; Poesía panameña; Evtuchenco]. GI 9 mayo 1976: 5.

Libros. [Antonio Machado; Pedro Salinas; Juan Ramón Jiménez; Ernesto Cardenal]. GI 16 mayo 1976: 6.

Libros. [Carmen Bravo Villasante. Veinticinco mujeres a través de sus cartas; Elsa de Llarena. Catorce mujeres escriben cuentos; Virginia Woolf, en la GaFCE; Mallarmél. GI 30 mayo 1976: 5.

Libros. [Surrealismo; Traducciones; Rev. Europe]. GI 6 jun. 1976: 3.

Libros. [Manuel González Calzada. A esas horas y...; Los escollos de la edición de originales; Dámaso Murúa]. GI 13 jun. 1976: 5.

Libros. [Paul Verlaine; Malkah Rabell-

Madelaine; La Intemacional, letra y música]. GI 20 jun. 1976: 7.

Libros. [Regino Pedroso, Raymundo Lazo y Salvador Bueno, cubanos]. GI 27 jun. 1976: 5.

Libros. [Juan Carlos Onetti; José Emi-

lio Pacheco; Ulalume González de León]. GI 4 jul. 1976: 5

Libros. [Roberto Femández Iglesias; La editorial Obra Citada]. GI 11 jul. 1976: 7.

Libros. [Estudios de y sobre el Quijote]. Gl 18 jul. 1976: 5.

Libros. [Citas de Carlos Fuentes y de Reyes sobre el Quijote]. GI 25 jul. 1976: 5

Libros. [Revistas Sur, Intentos, Alquimista, Xilote, Manatí, Pireni y El Ciervo Herido]. GI 1o. ago. 1976: 13.

Libros. [José Luis González y la poesía negra; Traducciones]. GI 8 ago. 1976: 15.

"Lezama Lima: la soledad creadora.", Libros. [Recuerda la muerte de Federico García Lorca; Citas de Gibson y de Daniel Sueiro en relación 
a García Lorca]. GI 15 ago. 1976: $3,17$.

Libros. [García Lorca-Alberti; Asesinato de García Lorca]. GI 22 ago. 1976: 13.

Libros. [Manual de urbanidad; Cita una guía de lectura para la obra de Carpentier; Gabriel López Chiñas y su obra; Poesía por Cuba]. GI 29 ago. 1976: 19.

Libros. [José Roberto Cea, salvadoreño. Mester de picardía; Homenaje a Roque Dalton; Victoria Ocampo y la música; Alicia 'Tikis' Reyes]. GI 5 sep. 1976: 21.

Libros. [Rafael Cordero A. El tren de las diez; Juan Pascoe, editor; El ensayo como género]. GI 12 sep. 1976: 7.

Libros. [Maravillas de Boloña; Eliseo Diego]. GI 19 sep. 1976: 19.

Libros. [Dámaso Murúa y la música; Poema de Miguel Bustos Cerecedo a Nicanor Parra]. GI 26 sep. 1976: 21.

Libros. [Enrique Fierro. Breve suma; Luis Chumacero. Casa llena]. GI 3 oct. 1976: 17.

Libros. [Revistas El Telar y Baruiade]. Gl 17 oct. 1976: 15.

Libros. [Aurora Albornoz y Elena Andrés. Chile en el corazón; Jaime Sabines; La letra J]. GI 24 oct. 1976: 17.

Libros. [Carlos Pellicer. Esquemas para una oda tropical, ediciones; Literatura y sociedad en América Latina]. GI 31 oct. 1976: 23.

Libros. [Bertalina Peralta. Ragul; He-

rrera Zapién, traductor de Neruda; José Rubén Romero, editado en Cuba]. GI 7 nov. 1976: 21.

Libros. [Confederación de Escritores Latinoamericanos; Eds. de la UNAM; Rev. Manat!]. GI 14 nov. 1976: 17.

Libros. [Mailer y la guerra de Viet- nam; Rafael F. Muñoz murió antes de ocupar su puesto en la Academia Mexicana de la Lengua; La estatua de la libertad]. GI 21 nov. 1976: 21.

Libros. [René Acuña. Estudio del Rabinal Achi]. GI 28 nov. 1976: 19.

"Revueltas: sus mitologías." Comunidad 11 [México] nov. 1976: 565566.

"Malraux, una vida prodigiosa." GI 12 dic. 1976: 4.

Libros. [Daniel Valcárcel. La rebelión de Tupac Amaru; La muerte y los suplicios; La muerte de Darío]. GI 19 dic. 1976: 17.

"Notas en tomo al señor pensador." [Fernández de Lizardi], Libros. [Ma. Luisa Mendoza. Las cosas; Enrique González Rojo, hijo. El quintuple balar de los sentidos]. GI 26 dic. 1976: 12.

Libros. [Autores musicalizados: Miguel Ramos Carrión, José de Antequera y Castro, Efrén Rebolledo y Manuel J. Othón]. GI 2 ene. 1977: 11.

Libros. [Mujeres militantes]. GI 9 ene. 1977: 16.

Libros. [Salvador Elizondo. Museo poético; Raúl Salinas V. Las cien peores poesías; Maximiliano Salazar; Anécdotas sobre Ma. del Carmen Millán]. GI 16 ene. 1977: 17.

Libros. [Alberti. Poesía 1924-1930; Ma. Luisa Mendoza. Carmen Serdán; Beatriz Reyes Nevares. Ángela Peralta. y Rosario Castellanos; Andrés González Pagés; Pedro Orgambide]. GI 23 ene. 1977: 23.

Libros. [Anécdotas en torno a Casa de las Américas]. GI 30 ene. 1977: 23.

Libros. [Roberto Fernández Retamar. Calibán; Ezequiel Martínez Estrada]. Gl 6 feb. 1977: 21.

Libros. [Roque Dalton. Pobrecito poe- 
ta que era yo; Muere Gonzalo Araigo, creador del nadaismo; Siglas]. GI 27 feb. 1977: 10.

Libros. [ Los diccionarios y sus errores]. GI 6 mar. 1977: 19.

"Carlos Pellicer: una poesía solar." CuM 9 mar. 1977: xi.

Libros. [Carlos Luis Fallas. Manita Yunai; Los plátanos en la literatura]. GI 13 mar. 1977: 17.

"Carlos, en su otro paisaje." [Carlos Pellicer], Libros. [Plagios literarios; Carta en relación al Premio Ricardo Miról. GI 20 mar. 1977: 3. 19.

Libros. [Pedro Orgambide, Historias de tangos y corridos; Vida y memoria del guerrillero $\mathbb{N}$. Villafañe; Herrera Zapién, traductor]. GI 27 mar. 1977: 20.

Libros. [Demetrio Aguilera Malta. Don Goyo; Cita a Ferlinghetti hablando de poesía; Fernández Moreno, argentino]. GI 3 abr. 1977: 17.

Libros. [Héctor Valdés. Poetisas mexicanas; Marta Acevedo. Ni diosa ni mártir; Juana Meléndez de Espinosa. Acto que afirma; EH, datos autobiográficos]. GI 10 abr. 1977: 21.

Libros. [Gonzalo Arango. Retorno del libertador; Los estridentistas; El suspenso y lo policiaco]. GI 17 abr. 1977: 19.

Libros. [Anécdota de Carlos Illescas; Juan Marinello y Alberti; Benny Moré]. GI 24 abr. 1977: 7.

Libros. [Manuel Puig. Boquitas pintadas; La música de Agustín Lara; Recuerdo de Raymundo Lazo]. GI 30 abr. 1977: 17.

Libros. [Citas sobre Carlos Martínez Moreno y José Emilio Pacheco; Cita a Guinter Grass; A. RobbeGrillet; Luis Spota y la crítica]. GI 8 mayo 1977: 17.

Libros. [Rulfo y Usigli; Carta de Usi- gli en torno a Corona de sombra]. GI 15 mayo 1977: 19.

Libros. [Luis Cardoza y Aragón; Flaubert]. GI 22 mayo 1977: 19.

Libros. [Literatura sobre la represión. Gloria Guardia, centroamericana; Alicia 'Tikis' Reyes. ¿Qué pasó con las parcas?] GI 29 mayo 1977: 17.

Libros. [La novela y el suspenso; Macedonio Fernández]. GI 5 jun. 1977: 17.

Libros. [Manuel Bandeira y su obra; Alberti, traductor de Bandeira; Epígrafe de Alfonso Reyes]. GI 12 jun. 1977: 19.

Libros. [D.L. Pitty. El centro de la noche; Gloria Guardia, Manuel Orestes Nieto y otros escritores panameños; Su viaje a Panamá]. GI 19 jun. 1977: 15.

Libros. [Poetas; Rev. Versus]. GI 26 jun. 1977: 16.

Libros. [Macedonio Fernández; Cita un comentario de Novo sobre Carlos Fuentes y frags. de la obra de Fuentes]. GI 3 jul. 1977: 16.

Libros. [El zoológico de Chiapas y e] profesor Miguel Álvarez del Toro]. GI 10 jul. 1977: 21.

Libros. [Héctor Raúl Almanza. Huelga blanca; Cita el decálogo de Martínez Moreno sobre la novela]. GI 17 jul. 1977: 15.

Libros. [Carmen Castellote; García Narezo, editor, Las flores; La ciudad de Morelia]. Gl 24 jul. 1977: 21.

Libros. [Mariano Azuela]. GI 31 jul. 1977: 21.

Libros. [Rev. Mester de Picardía]. GI 7 ago. 1977: 19.

"Jaime Sabines revisitado." CuM [Siempre! 10 ago. 1977]. 19 ago. 1977: ii-iii.

Libros. [La ciudad como tema narrativo; José Agustín y Arturo Sotoma- 
yor]. GI 14 ago. 1977: 15.

Libros. [Vinicius de Moraes. Para vivir un gran amor; Trayectoria de Joaquín Antonio Peñaloza]. GI 21 ago. 1977: 21.

Libros. [José Herrera Petere]. GI 28 ago. 1977: 21.

Libros. [José Ma. Vargas Vila; Ramón Martínez Ocaranza; Josefa Murillo, seudónimos; Miguel Bustos Cerecedo, coeditor de la rev. El Ojo Literato]. GI 4 sep. 1977: 21.

Libros. [Maruxa Vilalta]. GI 11 sep. 1977: 11.

Libros. [Salvador Allende; Las viudas de Vallejo y Neruda no sueltan los inéditos]. Gl 18 sep. 1977: 17.

"Deslindes. Juan José Prado. Leyendas y tradiciones guanajuatenses." DdeMéx 19 sep. 1977: 2.

Libros. [Edmundo Font. Otra vez Guernica; Jaime G. Velázquez. Viajes de regreso; Eusebio Rubalcaba. Atmósfera de fieras; Macario Matus. Palabra desnuda; Revistas Hipócrita Lector y Disturbios]. GI 25 sep. 1977: 19.

Libros. [Juan Rejano. Alas de tierra; Raúl Leiva; Rodrigo Miró; Arístides Martínez Ortega]. GI 2 oct. 1977: 19.

Libros. [José Alvarado. Tiempo guardado. y Cuentos; Regino Pedroso, cubano]. GI 9 oct. 1977: 16.

Libros. [Aurora M. Ocampo. Cuentistas mexicanas siglo $X X$; $\mathrm{R}$ aquel $\mathrm{Ti}$ bol, esculturas de F. González Cortázar; Jesús Arellano y sus obras]. Gl 16 oct. 1977: 21.

Libros. [Ricardo Pozas. Juan Pérez Jolote; María Sabina; Aleixandre]. GI 23 oct. 1977: 21.

Libros. [Andrés Henestrosa y su obra, en especial, Espuma y flor de corridos mexicanos y los prólogos a ésta]. GI 30 oct. 1977: 17.

Libros. [Domitila. Si me permiten ha- blar; Silvia Molina. La mañana debe seguir gris]. GI 6 nov. 1977: 19.

"Aleixandre: poesía como labios.", Libros. [Federico Gamboa. Diario; Rodrigo Delgadillo León ('Delga León')]. GI 13 nov. 1977: 4, 19.

Libros. [Agustín Lanuza. Romances, tradiciones y leyendas de guanajuatenses; B. Brecht; Rev. Eco]. GI 19 nov. 1977: 17.

Libros. [La Zona Rosa como tema literario; Rev. Oso Hormiguero; Antonio Cisneros, Premio Casa de las Américas]. GI 27 nov. 1977: 17.

"Líneas sobre Octavio Paz." Sáb 3 dic. 1977: 15-16.

Libros. [León de Greiff, colombiano]. GI 4 dic. 1977: 19.

Libros. [José Joaquín Blanco. Se llamaba Vasconcelos; Ernesto Cardenal]. GI 11 dic. 1977: 23.

Libros. [La colección Lunes de los hermanos González Casanova; El cuento como tema; Edmundo Valadés]. GI 18 dic. 1977: 17.

Libros. [Col. América Nueva de editorial Siglo XXI; Salvador Novo y el náhuatl; Diccionarios y libros sobre el náhuatl]. GI 24 dic. 1977: 15.

"Digno mexicano Rivera." [Diego Rivera]. Sáb 24 dic. 1977: 9.

Libros. [Gustavo Sainz. Compadre lobo; Alberto Molina. Los hombres color de silencio; Juan Pascoe. 51 poemínimos; López Velarde; Revistas Tierra Adentro y Pirgüín]. GI 31 dic. 1977: 19.

Libros. [José Moreno Villa; Virginia Woolf]. GI 8 ene. 1978: 15.

Libros. [Julio Torri, 'La cocinera'; Monterroso, traductor]. Gl 15 ene. 1978: 15.

Libros. [Cita un comentario sobre Diego Rivera]. GI 22 ene. 1978: 15. 
Libros. [Anécdota sobre José Ferrel; Marco A. Campos; Desaparece la rev. Comunidad]. GI 29 ene. 1978: 19.

Libros. [Pedro Henríquez Ureña]. $G I$ 5 feb. 1978: 16.

"Presentación." [Gheli Zárate, periodista peruana]. SBA 8 feb. 1978: 2 . Libros. [Edmundo O'Gorman. La invención de América; Carlos Monsiváis. Amor perdido]. GI 12 feb. 1978: 17.

Libros. [B. Traven; Lilliam Hellman]. GI 5 mar. 1978: 15.

Libros. [José Martí. Ismaelillo; Silves-

tre Revueltas. Epistolario; Mario Benedetti; Literatura cubana]. GI 12 mar. 1978: 17.

Libros. [Ricardo Repilado; Reis López

Tijerina; Ángela Davis]. GI 19 mar. 1978: 17.

Libros. [Nicolás Guillén]. GI 26 mar. 1978: 19.

Libros. [Beltrán Morales. Cruces; César Fernández Moreno. Ambajes; Jorge Turner. Viento de agua]. GI 2 abr. 1978: 17.

Libros. [Raúl Prieto. Madre academia; Porfirio Barba Jacob y su obra]. GI 9 abr. 1978: 23.

Libros. [Jacques Lafaye. Quetzalcó-all y Guadalupe; David Alfaro Siqueiros. Me llamaban el coronelazo]. GI 23 abr. 1978: 15.

Libros. [Fernández Retamar y Fernández Iglesias]. GI 30 abr. 1978: 17.

Libros. [Col. Material de Lectura, UNAM]. GI 7 mayo 1978: 17.

Libros. [Aurora de Albornoz entrevista a Alberti]. GI 14 mayo 1978: 15.

Libros. [El corrido]. GI 21 mayo 1978: 15.

Libros. [Mario Quintana, poeta brasileño; Las flores y los árboles]. GI 28 mayo 1978: 19.

Libros. [Guillermo García Oropeza.
La balada de Gary Cooper; Ernesto Cardenal, musicalizado; Enrique González Rojo hujo, fílósofo]. GI 4 jun. 1978: 17.

Libros. [Los carteles de protesta en Argentina, Uruguay y Nicaragua]. GI 11 jun. 1978: 17.

"Esta poesía de Mariángeles Comesaña.", Libros. [Carlos Fuentes. La cabeza de la hidra y Zona sagrada; Malraux]. GI 18 jun. 1978: 12, 21.

Libros. [Joaquín García Monge; Olga Arias. Mínimo cardumen; German List Arzubide. El robo de la mujer de Rubens; Jesús Silva Herzog]. GI 25 jun. 1978: 15.

Libros. [Literatura chicana; Borges]. GI 2 jul. 1978: 17.

Libros. [Quino. Bien gracias iY usted?; La política]. GI 9 jul. 1978: 19.

Libros. [Carlos Pellicer. Voz y luz del trópico; Tarascos y olmecas]. GI 16 jul. 1978: 19.

Libros. [Diccionario de religiones; Pedro Mir. Meridiano 70, antología de poesía dominicana; E. Adolfo Westphalen: Dos soledades]. GI 23 jul. 1978: 19.

Libros. [Alejandro Rossi. Manual del distraido; Raquel Tibol. Frida Kahlo; Rev. Europe]. GI 30 jul. 1978: 21.

Libros. [Rubén Bonifaz Nuño; César Dávila Andrade; Álvaro Mutis]. GI 6 ago. 1978: 17.

Libros. [Franz Kafka. Cartas a Felice; Rev. Zona]. GI 13 ago. 1978: 17. Libros. [Guadalupe Dueñas. Imaginaciones; Pedro Mir; José Luis González; Guillermo Samperio]. GI 27 ago. 1978: 15.

Libros. [Nathaniel Hawthorne. La hija de Rappaccini. Versión teatral Octavio Paz; 'El brindis del bohemio'; Antonio Plaza]. GI 3 sep. 1978: 15. 
Libros. [La poesía; El unicomio y otros temas]. GI 10 sep. 1978: 15.

Libros. [Nicolás Guillén; J. Roumain; Rafael Salinas; Cicerón]. GI 17 sep. 1978: 17.

Libros. [Saúl Ibargoyen y Jorge A. Boccanera. Poesía rebelde de Latinoamérica; Ernesto Cardenal, antologador]. GI 24 sep. 1978: 15.

Libros. [Juan José Arrom; Tolstoi]. GI 1o. oct. 1978: 17.

Libros. [Franz Kafka; Gastón García Cantú]. GI 8 oct. 1978: 15.

Libros. [John Reed. Alborada de la Revolución en Asia; Cortázar; Alfonso Caso]. GI 15 oct. 1978: 16.

Libros. [Roberto Fermández Retamar;

J. Cureu, guyanés; Rafael Góchez Sosa y Tirso Canales, salvadoreños; Gregorio Selser; Demetrio Aguilera Malta; Rev. Litoral]. GI 22 oct. 1978: 15.

Libros. [Ermilo Abreu Gómez. Canek; Ernesto Cardenal. Nueva aniología poética]. GI 29 oct. 1978: 15.

Libros. [Carlos Isla. Copias al carbón;

Gabriel Zaid. Canciones de vidy apati; Octavio Navaro. Las jornadas del escriba; Fedro Guillén; Las literaturas yucateca y salvadoreña]. GI 5 nov. 1978: 15.

Libros. [Fayad Jamis, traductor; Caldwell]. GI 12 nov. 1978: 14.

Libros. [Carmen de la Fuente. Procesión de la memoria; Margarita Paz Paredes. Litoral del tiempo; Octavio Novaro. Xavier Villaurrutia en persona y en obra; Antonio Cisneros]. GI 19 nov. 1978: 15.

Libros. [Mario Benedetti. Inventario; Rafael Giménez Siles, editor; Caldwell; José Lezama Lima]. GI 26 nov. 1978: 15.

Libros. [Eduardo Torres, guatemalteco; Cuadernos de Lectura, UNAM]. GI 3 dic. 1978: 15.

Libros. [Literaturas del Perú y de El
Salvador; Hildebrando Pérez, peruano]. GI 10 dic. 1978: 15.

Libros. [Neruda. Residencia en la tierra; Caldwell]. GI 17 dic. 1978: 17.

Libros. [Fernando Benítez; Lewis Carroll. GI 24 dic. 1978: 17.

Libros. [Frida Varinia Ramos, hija de Raymundo Ramos; Margaret Randall, estudiosa de la literatura cubana; Roberto Dávila; Rev. Vivencias]. GI 31 dic. 1978: 15.

Libros. [Alberto Huerta. Ojalá estuvieras aqui; Mujeres en la Academia; Ramón Martínez Ocaranza]. GI 7 ene. 1979: 17.

Libros. [Miguel Bustos Cerecedo; Tocqueville; Revistas Gaveta y Alaluz, ésta, dirigida por Ana Ma. Fagundo]. GI 14. ene. 1979: 15.

Libros. [Juan Grigulevich. Pancho Vi-

lla; Luis E. Rivera. $K$; Haroldo Conti; Oscar Chávez y Óscar Chávez Ramírez, trovadores; Instituto Nacional de Cultura de Panamá]. GI 21 ene. 1979: 15.

Libros. [Caldwell editado por José Ferrel; Marco Antonio Campos]. GI 28 ene. 1979: 15.

Libros. [Salvador Molina. Rómulo Gallegos, su obra y exilio en Morelia; Arturo Molina. Viñetas del sesquicentenario; Carpentier; Alberti; Los hispanistas soviéticos; Revistas La Carpa, Caligrama y El Centavo]. GI 4 feb. 1979: 15.

Libros. [Carpentier; Pacifistas; El Lago de Cuitzeol. GI 11 feb. 1979: 17.

Libros. [Carpentier. La consagración de la primavera; Jesús Arellano y los talleres literarios; Victoria Ocampo]. GI 18 feb. 1979: 17.

Libros. [Marco Antonio Campos; Carpentier; Fedro Guillén]. GI 25 feb. 1979: 15.

"Un centavito." Centavo 100. feb. 1979: 18. 
Libros. [Carta y soneto de Cayetano Córdova Iturbide; Ezequiel Martínez Estrada; Rev. Cantera]. GI 4 mar. 1979: 15.

Libros. [Margaret Randall. Doris Tijerino: Inside the Nicaraguan Revolution. Carlota y No se puede hacer la Revolución sin nosotras; Otto Raúl González. Tun y chirimía; Ricardo Cortés Tamayo. Crónica de una jornada cultural en Yucatán; D.L. Pitty; García Márquez; Hemingway; Arturo Azuela]. GI 11 mar. 1979: 15.

Libros. [Francisco Paniagua Gurría. En el valle de los espejos; Oscar Wong. Fragmentaciones; Carpentier, polémica; Editorial La Gárgola, de Yolanda Argudín, Margarita Paz Paredes y Antonio Castañeda]. GI 18 mar. 1979: 15.

Libros. [Eduardo Lizalde. El tigre en la casa; Hemingway]. GI 25 mar. 1979: 15.

Libros. [Julián Gascón Mercado. Yatrogénesis poética; Jean Meyer. La cristiada; Julio Frenk. Triptofanito; Los 200 libros de Asimov; Félix Pita Rodríguez; Rev. Barandal]. GI 1o. abr. 1979: 16-17.

Libros. [Hojas literarias Cantera y La Riscucha; Carlos Mejía Godoy]. GI 8 abr. 1979: 16, 17.

Libros. [Mario Benedetti y Casa de las Américas]. GI 15 abr. 1979: 16-17.

Libros. [La poesía; Gerado Deniz; Datos sobre Lorenzo Varela]. GI 22 abr. 1979: 15.

Libros. [Antonio Cisneros. El libro de Dios y de los húngaros; Brígido Redondo. Escritores campechanos contemporáneos; Esteban Durán Rosado. Crónicas retrospectivas; Josefina Vicens. El libro vacio; Elsa (Josefina) Tío]. GI 6 mayo 1979: 17.
Libros. [Ricardo Garibay. Las glorias del gran Púas; Rev. Cambio; Carpentier; Sandino; Comala]. GI 13 mayo 1979: 15.

"La casa de todos los hombres libres." [Discurso en Casa de las Américas]. Libros. [Julio C. Schara; B. Brecht; Réquiem por Carlos Pellicer; Nuestro idioma]. GI 20 mayo 1979: 6-7, 16-17.

Libros. [Carlos Monsiváis. Antología de la crónica; Olivia de Montelongo. El alma y las uvas de nostalgia; Eduardo Galeano fue E. Hughes Galeano hasta 1959; Libros de Carpentier; Elva Macías; Silvia Molina]. GI 27 mayo 1979: 16-17.

Libros. [Elena Jordana. Poemas no mandados; El significado de SanEv-Ank]. GI 3 jun. 1979: 15.

Libros. [Rubén Salazar Mallén. Apun-

tes para una biografía de sor Juana Inés de la Cruz; Eric Norman (Pedro Ferris). Dioses, demonios y ovnis; Rev. Dintal, de Carmen Castellote]. GI 10 jun. 1979: 15.

Libros. [Andrés Ordóñez. En modo menor; Carpentier. El arpa y la sombra; Eugenio Chellet. Instante recobrado]. GI 17 jun. 1979: 15.

Libros. [José Revueltas y su columna 'El alicante pinto', en El Popular; datos y recuerdos sobre él]. Gl 24 jun. 1979: 15.

Libros. [Obra y recuerdos de Usigli; Usigli y Bemard Shaw]. GI 1o. jul. 1979: 15.

Libros. [Yolanda Argudín. Esperando a los bárbaros; Francisco Serrano. Canciones antiguas; Juan Gelman. Los poemas de Sidney West; Mario B. Millán. Palabras amorosas a la vida; Cuentos chinos; Bartra y Paz, traductores de Apollinaire; Carlos Isla]. GI 8 jul. 1979: 15.

Libros. [Emesto Sábato. Tango; David 
Viñas, Premio Casa de las Américas 1967; El 'Che']. GI 15 jul. 1979: 15.

Libros. [Revistas Pegaso, Gladios y Thesis]. GI 22 jul. 1979: 15.

Libros. [Alfredo Márquez Campos. Escala en el tiempo. Yo no haría esu. y Lejos quedó el pueblo; Rodolfo Walsh. Operación masacre; Agustín Ramos. Al cielo por asalto; Maruxa Vilalta. Historia de él; Rev. Chanelcullo, dirigida por Dante Medina; Pablo Soler dirige la rev. Águilas]. GI 29 jul. 1979: 15.

Libros. [Fernando Del Paso. Palinuro de México; Federico Patán. Calas menores; Alfredo Cardona Peña. La entrevista literaria y cultural]. GI 5 ago. 1979: 15.

Libros. [Dámaso Murúa. El Güilo mentiras; Mario Benedetti. La tregua; Sergio Ramírez. Charles Atlas también muere; Jesús Lara. La poesía quechua; Carpentier. La música en Cuba; Mariátegui. Obra política]. GI 19 ago. 1979: 15.

Libros. [Juan Goytisolo, 1909-1979;

Oscar Collazos; Arturo Serrano Plaza, antología de su obra; Juan Rejano]. GI 26 ago. 1979: 15.

Libros. [Saúl Yurkievich. Fundadores de la nueva poesía Latinoamericana; Gabriel Miró]. GI 9 sep. 1979: 17.

Libros. [Alberti; Blas de Otero]. GI 15 sep. 1979: 17.

Libros. [Andrés Ordóñez. Hoy como nunca; Francisco Gutiérrez Lomasto. Llano invisible, plagio a Los hombres del alba. de EH]. GI 23 sep. 1979: 17.

Libros. [José Hernández. Martín Fierro; Carlos Fuentes]. GI 30 sep. 1979: 15.

Libros. [Su viaje por España; Aleixandre]. GI 7 oct. 1979: 15.
Libros. [Paco Ignacio Taibo I. Fuga, hierro y fuego; Susana Glantz. $M a$ nuel, una biografía política; $\mathrm{Pa}-$ ciencia Ontañón de Lope. Estudios sobre Gabriel Miró; Benita Galeana acusa de plagio a Juan de la $\mathrm{Ca}$ badal. GI 14 oct. 1979: 15.

Libros. [Juan de la Cabada. Cuentos del camino]. GI 21 oct. 1979: 15.

Libros. [Miguel Donoso Pareja. Todo el destino a pie, antología; Mario Benedetti. Poesía trunca; Alfonso Sierra Partida. Ignacio Ramírez: espada y pluma; Alberti; Rev. Ábside]. GI 28 oct. 1979: 15.

Libros. [Angela Figuera Aymerich. Antología total; José Muñoz Cota. Romances de la hoz y del martillo; Gaspar García Laviana. Cantos de amor y de guerra; Arturo Sotomayor. Cortés según Cortés; James G. Frazer. La rama dorada; Roberto Sosa, hondureño]. GI 11 nov. 1979: 15.

Libros. [Benita Galeana. El peso mocho; Rev. México Moderno]. Gl 18 nov. 1979: 14-15.

Libros. [Don Juan Manuel, el conde Lucanor; Alicia Delaval. Retorno al gris; Carmen Castellote. Con suavidad de frio; Federico Campbell. Pretexta; Rubén Bonifaz Nuño; Acapulco]. GI 25 nov. 1979: 16-17.

"El oro que sí rehíce." [Literatura de los Siglos de Oro]. $C U$ nov.-dic. 1979: 23.

Libros. [Rafael Alcérrega. Fisuras del silencio; James W. Robb. El estilo de Alfonso Reyes; Carlos Pellicer. Hora de junio; Rev. Texto Crítico]. GI 2 dic. 1979: 16-17.

Libros. [César Young Núñez. Óscar Wilde; Mariátegui; Raúl Prieto. Perlas japonesas; Rev. Caligrama]. GI 9 dic. 1979: 15. 
Libros. [Revistas Cachora, Barandal, Dos Puntos y Araucaria]. GI 16 dic. 1979: 15.

Libros. [Eduardo Lizalde. Caza mayor; Emesto Cardenal, vida y obra; Semblanza de Salomón de la Selva; Alberti]. GI 23 dic. 1979: 15.

Libros. [Beatriz Espejo. Muros de azogue; Ma. José de Chopitea.
Sola; Martín Adán. Obra poética; Saúl Ibargoyen. Palabra por palabra; Roberto Bolaño. Muchachos desnudos bajo el arcoiris de fuego; Revistas Cartapacios, Rehilete, Los Universitarios y Plural]. GI 30 dic. 1979: 15.

“¿Cuándo y dónde conocí a Juan de la Cabada?" GaP. dic. 1979: 12. 